\title{
Towards an empirical vulnerability function for use in debris flow risk assessment
}

\author{
S. Fuchs, K. Heiss, and J. Hübl \\ Institute of Mountain Risk Engineering, University of Natural Resources and Applied Life Sciences, Vienna, Austria
}

Received: 5 June 2007 - Revised: 29 August 2007 - Accepted: 29 August 2007 - Published: 30 August 2007

\begin{abstract}
In quantitative risk assessment, risk is expressed as a function of the hazard, the elements at risk and the vulnerability. From a natural sciences perspective, vulnerability is defined as the expected degree of loss for an element at risk as a consequence of a certain event. The resulting value is dependent on the impacting process intensity and the susceptibility of the elements at risk, and ranges from 0 (no damage) to 1 (complete destruction). With respect to debris flows, the concept of vulnerability - though widely acknowledged - did not result in any sound quantitative relationship between process intensities and vulnerability values so far, even if considerable loss occurred during recent years.

To close this gap and establish this relationship, data from a well-documented debris flow event in the Austrian Alps was used to derive a quantitative vulnerability function applicable to buildings located on the fan of the torrent. The results suggest a second order polynomial function to fit best to the observed damage pattern. Vulnerability is highly dependent on the construction material used for exposed elements at risk. The buildings studied within the test site were constructed by using brick masonry and concrete, a typical design in post-1950s building craft in alpine countries. Consequently, the presented intensity-vulnerability relationship is applicable to this construction type within European mountains. However, a wider application of the presented method to additional test sites would allow for further improvement of the results and would support an enhanced standardisation of the vulnerability function.
\end{abstract}

\section{Introduction}

The term natural hazard implies the occurrence of a natural condition or phenomenon which threats disastrous in a defined space and time. Notwithstanding from these definitions, some authors characterise the "natural process" as "hazard", and the "natural hazard" as "disaster", and argue that hazards are natural, but in general, disasters are not, and that disasters should not be seen as inevitable outcome of a hazard's impact (O'Keefe et al., 1976). They stress on the conditions of people which make it possible for a hazard to become a disaster (Cannon, 1993). This includes the extent and types of people's vulnerability, in combination with the technical issue of how society deals (or does not deal) with the hazard in terms of mitigation and preparedness.

With respect to natural hazards, different conceptualisations have not only evolved in time, they also reflect the approach of different disciplines involved. In early works natural hazards have been expressed as those elements in the physical environment harmful to men (Burton and Kates, 1964) or an interaction of people and nature (White, 1973). Modern approaches characterise natural hazards as physical events causing an impact on human beings and their environment (e.g., Alexander, 1993) and, more general, they are defined as the probability of occurrence of a potentially damaging phenomenon (United Nations, 2004).

The term vulnerability is closely related to natural hazards, and is used in hazard and disaster management in a large number of ways. Vulnerability is commonly related to the consequences of a natural hazard. These consequences are generally measured in terms of damage or losses, either on a metric scale (e.g., as monetary unit), or on an ordinal scale based on social values or perceptions and evaluations. This is not necessarily a matter of ambiguity or semantic drift, but the result of different disciplinary foci. Essentially, these different uses have invisible, implied adjectives preceding them, resulting in e.g. structural engineering vulnerability, lifeline infrastructural vulnerability, communications system vulnerability, macro-economic vulnerability, regional economic vulnerability, commercial vulnerability (including insurance exposure), and social vulnerability (Wisner, 2004). Consequently, two diverse perspectives on the concept of vulnerability exist; (1) the perspective from social science and (2) the (technical) perspective from natural science.

Correspondence to: S. Fuchs

(sven.fuchs@boku.ac.at)

Published by Copernicus Publications on behalf of the European Geosciences Union. 
1. As Cutter (1996) stated, there are no unique definitions of vulnerability in social sciences. Multiple definitions (partly also addressing technical meanings) are reviewed and listed by Cutter (1996) and Weichselgartner (2001), see Table 1. Approaches in social sciences not only differ between several degrees of voluntariness when dealing with natural hazards, but also consider individual as well as social influences, filtered by certain conditions that determine an individual's perception of risk. Depending on various guiding elements such as probability of occurrence, extent of damage, perception, uncertainty, ubiquity, persistence, reversibility, time delay, and mobilisation potential (German Advisory Council on Global Change 1998), the degree of vulnerability may considerably change. A major difficulty is that "not only people are different, but they are changing continuously, both as individuals and as groups. This constant change within the human system (...) interacts with the physical system to make hazard, exposure, and vulnerability all quite dynamic" (Mileti, 1999:119). Most problems resulting from hazard assessment are related to the difficulty of individuals in dealing with low probabilities of rare events (Kunreuther et al., 2001). Individual risk perception, passed through a communication filter, finally leads to a risk assessment as well as accompanying adaptation processes, the latter are either efforts to control hazards or to reduce vulnerability to hazards (Burton et al., 1993).

2. From a natural science perspective, vulnerability is usually considered as a function of a given process intensity towards physical structures; and is therefore related to the susceptibility of elements at risk. Thus, vulnerability - often referred to as "technical" or "physical" vulnerability in this context - is defined as the expected degree of loss for an element at risk as a consequence of a certain event (Varnes, 1984; Fell, 1994). Consequently, the vulnerability value ranges from 0 (no damage) to 1 (complete destruction). Its assessment involves in many cases the evaluation of several different parameters and factors such as building materials and techniques, state of maintenance, presence of protection structures, presence of warning systems and so on (Fell, 1994; Fell and Hartford, 1997). On the impact side, empirical process parameters such as the intensity have to be analysed based on theories of probability, which is usually undertaken by mapping the geomorphologic disposition and the extent of previous events, and by modelling (defined design) events.

Even if the latter perspective of vulnerability had been subject to extensive research and practical application for the last decades, considerable gaps still exist with respect to standardised equations allowing for a wider application of technical vulnerability assessments (e.g., Glade 2003). This has to be attributed to the overall lack of data, in particular concerning losses caused by alpine natural hazards, often as a result of missing empirical quantification (Douglas, 2007). Recently, promising approaches for a quantification of vulnerability have been made by Wilhelm (1997), Borter (1999) and Barbolini et al. (2004) with respect to avalanches and rock fall processes, respectively. However, sound suggestions for landslides and torrent processes are still outstanding, even if these processes caused major losses in the Alps in recent years (e.g., Fraefel et al., 2004; Romang, 2004). In the following section, the current state of the art in vulnerability assessment for torrent processes is summarised, focussing on debris flows.

\section{State of the art}

From the natural science perspective, vulnerability assessment can be split into two main procedures, requiring fairly different methods and assumptions: estimation of the vulnerability of life and property.

Despite its importance, defining the degree of loss of human life has rarely been considered and implemented into landslide risk management, perhaps due to the intrinsic difficulty of its objective definition. Only recently some authors have approached the problem, largely relying upon considerations on the host structures and infrastructures (Leone et al., 1996), population census data such as density, education level or average age (Rautela and Lakhera, 2000; Liu and Lei, 2003) or consequence analysis (Bell and Glade, 2004). In the practical application, vulnerability is often related to exposure, which is defined as the maximum number of lives being present in endangered areas (e.g., Schuster and Fleming, 1986; Keiler et al., 2005).

The definition of the vulnerability of tangibles (buildings, structures, infrastructures, cultivated or productive land) and natural assets has been slightly more successful. Within recent years, several attempts have been made to address vulnerability issues in landslide risk assessment (Glade, 2003). In the subsequent compilation, the most promising suggestions for the assessment of vulnerability are ranked step-bystep from qualitative to quantitative approaches.

1. Already in the mid-1990s, Leone et al. $(1995,1996)$ chose an approach for the assessment of vulnerability by setting up a vulnerability matrix based on damage intensities and the respective resilience of the elements at risk towards landslides. The type of damage was described qualitatively with respect to possible degrees of structural failure (buildings) and necessary volumes of repair material (roads). The corresponding vulnerability was described by a numerical value; however, the origin of these numbers was not clearly stated and the resulting numbers were not linked to process intensities. Starting from similar data, Finlay (1996) proposed a methodology based on historical records to assign a 
Table 1. A compilation of different definitions of the term vulnerability with respect to natural hazards research (adopted and extended from information in Cutter 1996 and Weichselgartner 2001).

\begin{tabular}{|c|c|}
\hline Source & Definition \\
\hline Gabor and Griffith (1980) & $\begin{array}{l}\text { Vulnerability is the threat (to hazardous materials) to which people are exposed (including chemi- } \\
\text { cal agents and the ecological situation of the communities and their level of emergency prepared- } \\
\text { ness). Vulnerability is the risk context. }\end{array}$ \\
\hline Timmerman (1981) & $\begin{array}{l}\text { Vulnerability is the degree to which a system acts adversely to the occurrence of a hazardous } \\
\text { event. The degree and quality of the adverse reaction are conditioned by a system's resilience (a } \\
\text { measure of the system's capacity to absorb and recover from the event). }\end{array}$ \\
\hline Petak and Atkisson (1982) & $\begin{array}{l}\text { The vulnerability element of the risk analysis involved the development of a computer-based ex- } \\
\text { posure model for each hazard and appropriate damage algorithms related to various types of build- } \\
\text { ings. }\end{array}$ \\
\hline UNDRO (1982) & $\begin{array}{l}\text { Vulnerability is the degree of the loss to a given element or set of elements at risk resulting from } \\
\text { the occurrence of a natural phenomenon of a given magnitude. }\end{array}$ \\
\hline Susman et al. (1983) & Vulnerability is the degree to which different classes of society are differentially at risk. \\
\hline Varnes (1984) & $\begin{array}{l}\text { Vulnerability means the degree of loss to a given element or set of elements at risk resulting from } \\
\text { the occurrence of a natural phenomenon of a given magnitude. It is expressed on a scale from } 1 \\
\text { (no damage) to } 1 \text { (total loss). }\end{array}$ \\
\hline Kates (1985) & Vulnerability is the "capacity to suffer harm and react adversely". \\
\hline Pijawka and Radwan (1985) & $\begin{array}{l}\text { Vulnerability is the threat or interaction between risk and preparedness. It is the degree to which } \\
\text { hazardous materials threaten a particular population (risk) and the capacity of the community to } \\
\text { reduce the risk or adverse consequences of hazardous materials releases. }\end{array}$ \\
\hline Bogard (1989) & $\begin{array}{l}\text { Vulnerability is operationally defined as the inability to take effective measures to insure against } \\
\text { losses. When applied to individuals, vulnerability is a consequence of the impossibility or im- } \\
\text { probability of effective mitigation and is a function of our ability to detect hazards. }\end{array}$ \\
\hline Mitchell (1989) & Vulnerability is the potential for loss. \\
\hline Liverman (1990) & $\begin{array}{l}\text { Distinction between vulnerability as a biophysical condition and vulnerability as defined by po- } \\
\text { litical, social and economic conditions of society. Argumentation for vulnerability in geographic } \\
\text { space (where vulnerable people and places are located) and vulnerability in social space (who in } \\
\text { that place is vulnerable). }\end{array}$ \\
\hline Downing (1991) & $\begin{array}{l}\text { Vulnerability has three connotations: it refers to a consequence (e.g., famine) rather than a cause } \\
\text { (e.g., drought); it implies an adverse consequence (e.g., maize yields are sensitive to drought; } \\
\text { households are vulnerable to hunger); and it is a relative term that differentiates among socioeco- } \\
\text { nomic groups or regions, rather than an absolute measure or deprivation. }\end{array}$ \\
\hline UNDRO (1991) & $\begin{array}{l}\text { Vulnerability is the degree of the loss to a given element or set of elements at risk resulting from } \\
\text { the occurrence of a natural phenomenon of a given magnitude and expressed on a scale from } \\
0 \text { (no damage) to } 1 \text { (total loss). In lay terms, it means the degree to which individual, family, } \\
\text { community, class or region is at risk from suffering a sudden and serious misfortune following an } \\
\text { extreme natural event }\end{array}$ \\
\hline Dow (1992) & $\begin{array}{l}\text { Vulnerability is the differential capacity of groups and individuals to deal with hazards, based on } \\
\text { their positions within physical and social worlds. }\end{array}$ \\
\hline Alexander (1993) & $\begin{array}{l}\text { Human vulnerability is function of the costs and benefits of inhabiting areas at risk from natural } \\
\text { disaster. }\end{array}$ \\
\hline Cutter (1993) & $\begin{array}{l}\text { Vulnerability is the likelihood that an individual or group will be exposed to and adversely affected } \\
\text { by a hazard. It is the interaction of the hazard of place (risk and mitigation) with the social profile } \\
\text { of communities. }\end{array}$ \\
\hline Watts and Bohle (1993) & $\begin{array}{l}\text { Vulnerability is defined in terms of exposure, capacity and potentiality. Accordingly, the pre- } \\
\text { scriptive and normative response to vulnerability is to reduce exposure, enhance coping capac- } \\
\text { ity, strengthen recovery potential and bolster damage control (i.e., minimize destructive conse- } \\
\text { quences) via private and public means. }\end{array}$ \\
\hline Bohle et al. (1994) & $\begin{array}{l}\text { Vulnerability is best defined as an aggregate measure of human welfare that integrates environ- } \\
\text { mental, social, economic and political exposure to a range of potential harmful perturbations. } \\
\text { Vulnerability is a multilayered and multidimensional social space defined by the determinate, po- } \\
\text { litical, economic and institutional capabilities of people in specific places at specific times. }\end{array}$ \\
\hline
\end{tabular}


Table 1. Continued.

\begin{tabular}{|c|c|}
\hline Source & Definition \\
\hline Green et al. (1994) & $\begin{array}{l}\text { Vulnerability to flood disruption is a product of dependence (the degree to which an activity re- } \\
\text { quires a particular good as an input to function normally), transferability (the ability of an activity } \\
\text { to respond to a disruptive threat by overcoming dependence either by deferring the activity in time, } \\
\text { or by relocation, or by using substitutes), and susceptibility (the probability and extend to which } \\
\text { the physical presence of flood water will affect inputs or outputs of an activity). }\end{array}$ \\
\hline Dow and Downing (1995) & $\begin{array}{l}\text { Vulnerability is the differential susceptibility of circumstances contributing to vulnerability. Bio- } \\
\text { physical, demographic, economic, social and technological factors such as population ages, eco- } \\
\text { nomic dependency, racism and age of infrastructure are some factors which have been examined } \\
\text { in association with natural hazard. }\end{array}$ \\
\hline Gilard and Givone (1997) & Vulnerability represents the sensitivity of land use to the hazard phenomenon. \\
\hline Amendola (1998) & $\begin{array}{l}\text { Vulnerability (to dangerous substances) is linked to the human sensitivity, the number of people } \\
\text { exposed and the duration of their exposure, the sensitivity of the environmental factors, and the } \\
\text { effectiveness of the emergency response, including public awareness and preparedness. }\end{array}$ \\
\hline Comfort et al. (1999) & $\begin{array}{l}\text { Vulnerability are those circumstances that place people at risk while reducing their means of } \\
\text { response or denying them available protection. }\end{array}$ \\
\hline Weichselgartner and Bertens (2000) & $\begin{array}{l}\text { Vulnerability is defined as the condition of a given area with respect to hazard, exposure, pre- } \\
\text { paredness, prevention, and response characteristics to cope with specific natural hazards. It is a } \\
\text { measure of capability of this set of elements to withstand events of a certain physical character. }\end{array}$ \\
\hline Smith (2001) & $\begin{array}{l}\text { Human sensitivity to environmental hazards represents a combination of physical exposure and } \\
\text { human vulnerability - the breadth of social and economic tolerance available at the same site. }\end{array}$ \\
\hline Wisner et al. (2004) & $\begin{array}{l}\text { Vulnerability is defined as characteristics of a person or a group in terms of their capacity to antic- } \\
\text { ipate, cope with, resist and recover from the impact of a natural hazard. It involves a combination } \\
\text { of factors that determine the degree to which someone's life and livelihood are put at risk by a } \\
\text { discrete and identifiable event in nature or in society. }\end{array}$ \\
\hline Alexander (2005) & $\begin{array}{l}\text { The word "vulnerability" comes from the Latin verb vulnerare, "to wound", and signifies exposure } \\
\text { to physical or moral harm. }\end{array}$ \\
\hline
\end{tabular}

recommended value of vulnerability to buildings endangered by landslides in Hong Kong.

2. Cardinali et al. (2002) proposed an empirical qualitative approach in landslide risk analysis to be used within a GIS environment. The authors distinguished three different types of damage in combination with debris flow intensity, based on the inferred relationship between the intensity and type of the expected landslide, and the likely damage the landslide would cause:

- superficial (aesthetic, minor) damage, where the functionality of buildings and roads is not compromised, and the damage can be repaired, rapidly and at low cost;

- functional (medium) damage, where the functionality of structures or infrastructures is compromised, and the damage takes time and large resources to be fixed; and

- structural (total) damage, where buildings or transportation routes are severely or completely damaged, and require extensive (and costly) work to be fixed. In this category, demolition and reconstruction may be required.
However, with respect to the quantification of vulnerability, this approach did not suggest any values for the overall use in similar risk assessments.

3. Based on a case study in Australia Fell and Hartford (1997) proposed average vulnerability values particularly addressing vulnerability resulting from debris flows. These values were related to "the history of property damage (... ) in Australia and judgement" (Fell and Hartford, 1997:67), and were based on the qualitative description of the debris flow intensity (low, medium, high).

4. Michael-Leiba et al. (2003) performed an analysis of the vulnerability of residents, buildings, and roads to landslides (including debris flows) for the Cairns City Council (Australia) on a regional scale. For buildings on hill slopes, data were derived from the Australian Landslide Database (ALD 2007). The vulnerability for elements at risk susceptible to proximal debris flows was defined by a value of 1 , while the vulnerability for elements at risk susceptible to distal debris flows was set to the value of 0.1 .

5. Bell and Glade (2004) carried out a quantitative risk analysis for landslides in Iceland. Based on the studies 
in Glade (2003), information on vulnerability was analysed and modified, and respective levels of vulnerability were adapted to the situation in Iceland. The information on building susceptibility was derived from Jónasson et al. (1999). Vulnerability values used with respect to the debris flow intensities (low, medium, high) were comparatively high, which was attributed to the fact that Icelandic buildings for the most part are fairly weak timer constructions with some concrete elements, and with relatively large windows built towards the mountainside.

6. Borter (1999) presented a comprehensive approach for risk analyses focussing particularly on gravitational mass movements. This method is based on a three-step approach, depending on the scale of the risk analysis, and serves as a standard procedure for the mitigation of natural hazards in Switzerland. With respect to debris flows, Borter suggested vulnerability values for the building structure in dependence on the debris flow intensity (low, medium, high). The debris flow intensity is quantified according to BWW et al. (1997) for channel debris flows and according to BUWAL et al. (1997) for hillslope debris flows, and is based on a function of flow velocity and accumulation height, and the thickness of the mobilised soil layer, respectively. Borter's approach is - even if based on considerable assumptions - the most important attempt in the available literature since not only empirically deduced vulnerability values but also a range of magnitudes corresponding to these vulnerability values are provided.

7. Romang (2004) compiled a comprehensive work on the effectiveness of torrent mitigation measures in Switzerland. The vulnerability of buildings was derived by using data provided by the mandatory building insurer, and was based on the ratio between losses and reconstruction values. Related to medium debris flow intensities, the suggested vulnerability values of buildings were in accordance with Borter (1999). However, concerning high debris flow intensities, the values were considerably higher than those outlined in Borter (1999) and were attributed to the singularity of the event itself. The resulting damage susceptibility within highmagnitude events was specified with $73 \%$, which corresponds to a structural building vulnerability of 0.73 and exceeds the standard by approximately a factor of 1.5 .

To conclude, approaches from a technical point of view relate in particular to the "classical" risk analysis developed from safety engineering. Herein, landslide risk is a function of hazard, elements at risk, and vulnerability, whereby the latter is deduced from possible consequences of a process impact on the building structure.

The approaches for the evaluation of vulnerability presented in the previous section vary significantly in detail of

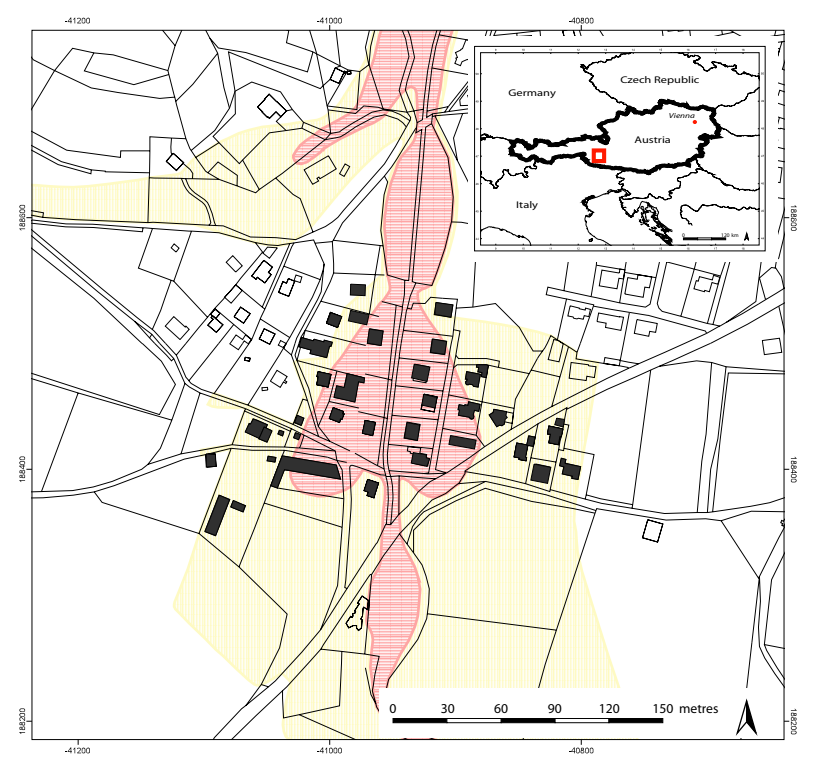

Fig. 1. Location of the test site in the Austrian Alps. Endangered buildings are shown by black colour; red and yellow hatching indicates the level of hazard in the respective hazard map compiled by the Austrian Torrent and Avalanche Control Service.

analysis and resulting numerical values (see Table 2). Although vulnerability is part of consequence evaluation, many approaches do neither specify the type of process they are applicable to (e.g., "landslides", debris flows, hyperconcentrated flows), nor the physical mechanisms (e.g., travel distance) or the structural resistance of an endangered object. In particular, information on the process intensity is often missing and is therefore only described semi-quantitatively.

Above all, in none of the studies the universal set and the sample taken for empirical calculations were clearly specified. Values for the vulnerability of buildings towards debris flows have so far been empirically estimated using relatively rare event documentation or assumptions. Moreover, the vulnerability was often estimated rather than based on damage collected in official authorities' or insurers' databases. A comparison of different studies is difficult due to the differing types of construction and construction materials used. Thus, studies conducted in Australia (e.g., Fell and Hartford, 1997) are hardly comparable to studies carried out in Switzerland (e.g., Borter, 1999; Romang et al., 2003) due to differing resilience of the values at risk. Thus, neither a unique method nor a vulnerability function is currently available for vulnerability assessments in landslide risk analysis, and in particular with respect to debris flows. The objective of this study is to partly close this gap by using data from a well-documented previous debris flow event that occurred in the Austrian Alps in August 1997. 
Table 2. Compilation of different suggestions related to an assessment of vulnerability of structural elements with respect to debris flows.

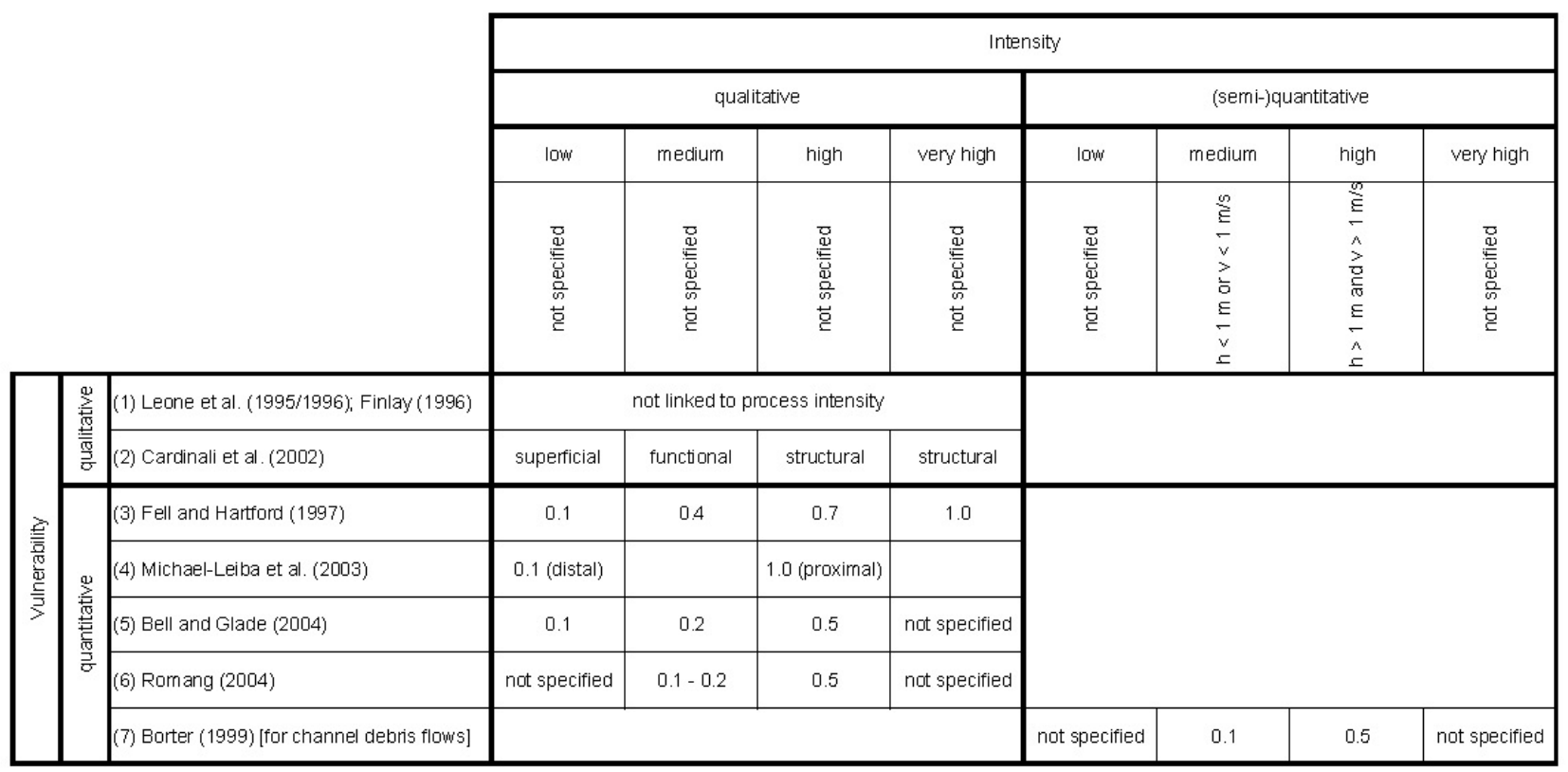

\section{Method}

The underlying concept applied in this work is relied on the concept of risk, which with respect to natural hazards is defined as a quantifying function of the probability of occurrence of a process and the related extent of damage, the latter specified by the damage potential and the vulnerability, see Eq. (1).

$$
R_{i, j}=f\left(p_{S i}, A_{O j}, v_{O j, S i}, p_{O j, S i}\right)
$$

Hence, specifications for the probability of the defined scenario $\left(p_{S i}\right)$, the value at risk affected by this scenario $\left(A_{O j}\right)$, the vulnerability of object $j$ in dependence on scenario $i$ $\left(v_{O j, S i}\right)$, and the probability of exposure of object $j$ to scenario $i\left(p_{O j, S i}\right)$ are required for the quantification of risk $\left(R_{i, j}\right)$. However, as stated in the previous section, information on the distribution of vulnerability of object $j$ in dependence on process intensities related to scenario $i$ is still missing so far. To establish this link, process intensities have to be joined to corresponding vulnerability values, i.e. buildings situated on the fan of a torrent.

\subsection{Test site}

The study area is situated in the Wartschenbach catchment in the Eastern Alps within the community of Nußdorf-Debant in the Drau valley, next to the city of Lienz, Austria (see Fig. 1). The catchment covers an area of $2.6 \mathrm{~km}^{2}$ between $670 \mathrm{~m}$ and $2113 \mathrm{~m}$ a.s.1. The geology is dominated by paragneiss and mica slate with a cover of quaternary glacial deposits. Due to the considerable amount of unconsolidated material, and due to the steep gradient of $30-40 \%$, the catchment is susceptible to erosion processes, in particular debris flows. Apart from minor events, considerable losses in the Wartschensiedlung village located on the fan occurred during periods of high precipitation in 1972, 1981, 1995, 1997 (2x), 1998, 1999, and 2000. For this study, the event of 16 August 1997 was used to analyse process characteristics and associated damage patterns (Fig. 2), since this event caused the severest damage and was therefore well documented. Spatial characteristics with respect to flooding depths and accumulation heights were available. Furthermore, the damage occurred during this event was completely registered in terms of monetary loss.

\subsection{Process characteristics of the August 1997 event}

The torrent process was triggered by an intensive precipitation event of $40 \mathrm{~mm}$ and $20 \mathrm{~min}$ duration. As a result, approximately $50000 \mathrm{~m}^{3}$ debris were mobilised in the upper part of the catchment. Roughly $50 \%$ of the material was re-deposited in the middle reaches of the torrent and in the retention basins, and nearly $20000 \mathrm{~m}^{3}$ were accumulated within the village located on the fan (Hübl et al., 2002), see Fig. 2. As a result, 15 buildings and one building yard were heavily damaged, and several additional buildings suffered minor losses. The process characteristics in the accumulation area were determined on the basis of the process documentation carried out subsequently after the event by the Austrian Torrent and Avalanche Control Service (Hübl et al., 2002), a federal institution operating throughout Austria to protect the population from torrents, erosion and avalanches. These data 


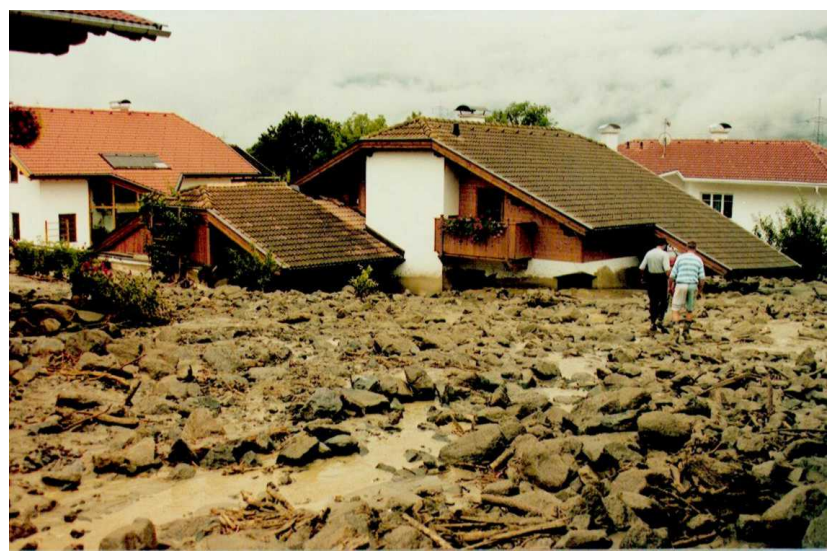

Fig. 2. The debris flow event of 16 August 1997 damaged buildings situated on the Wartschenbach fan, community of Nußdorf-Debant, Austria.

were supplemented by the analysis of data gathered from a re-calculation of the event, above all a reconstruction of the accumulation heights and flow depths on the fan. Accumulation heights and flow depths were used as proxies for the process intensities in the accumulation area within the test site. As a result, different process intensities were determined for the event, dividing the accumulation area into areas with different process severity.

\subsection{Values at risk}

The elements at risk - which were defined as those buildings within the Wartschensiedlung village located on the fan - were analysed with respect to their spatial location and extension using GIS. The size of the buildings was recorded from digital datasets of the communality administration and provided the basis for a monetary evaluation of the reconstruction values. These values were calculated using the volume of the buildings and average prices per cubic metre according to the type of building, as suggested by Kranewitter (2002) and Keiler et al. (2006). Following these suggestions, different price levels were applied, depending on the function of the buildings as well as on the number and kind of storeys. This information was extracted from the construction descriptions and updated by a field study. The average reconstruction value for every building resulted, using the 2002 price level.

The losses due to the event of 16 August 1997 were collected using information from the federal authorities. Since in Austria an obligatory building insurance against losses from natural hazards is not available so far, property losses are partly covered by a governmental fund ${ }^{1}$. Consequently, these losses are collected on an object level immediately after an event by professional judges. For this study, these data were adjusted to inflation and attributed to the information on every single element at risk using GIS.

\footnotetext{
${ }^{1}$ For information on this public fund, see the Appendix.
}

Table 3. Number, reinstatement value, loss, and vulnerability of the elements at risk in the Wartschenbach test site.

\begin{tabular}{llll}
\hline & Mean & Minimum & Maximum \\
\hline Reinstatement value [EUR] & 311000 & 190000 & 518000 \\
Loss [EUR] & 69000 & 1600 & 140000 \\
Vulnerability [1] & 0.22 & 0.008 & 0.27 \\
\hline
\end{tabular}

\subsection{Vulnerability}

The vulnerability of elements at risk was measured using an economic approach. The main criterion therefore is either the damage ratio, which describes the amount of damage related to the overall damage potential, or the damage susceptibility (vulnerability), which describes the amount of damage related to the specific damage potential of the considered element at risk, often referred to as loss severity. Following the latter definition, the vulnerability was derived from the quotient between the loss and the individual reinstatement value for each element at risk in the test site. In a second set of calculations, this ratio obtained for every single building in the test site was attributed to the process intensities of the 1997 event. As a result, a vulnerability function was developed, linking process intensities to object vulnerability values. Consequently, this vulnerability function was used as a proxy for structural resistance of buildings with respect to dynamic debris flow impacts, and thus was used for a spatially explicit assessment of debris flow susceptibly.

\section{Results and discussion}

Within the test site, 37 elements at risk are located, 16 of which suffered losses from the debris flow event in 1997. The reinstatement value according to the suggestions in Kranewitter (2002) summed up to nearly EUR 7.2 million, with a mean of EUR 311000 and a range from EUR 190000 to EUR 518000 (see Table 3). The overall damage amounted to approximately EUR 1.2 million, ranging from EUR 1600 to EUR 140000 for individual buildings (Table 3). The mean damage amounted to EUR 69000 per exposed building, the damage ratio in the Wartschenbach test site resulted in 0.22 . In Fig. 3, the intensity-vulnerability relation is shown for detached family houses, the predominant type of building in the test site. The prevailing construction is a brick masonry and concrete construction for the main floors and the cellar, respectively. The process intensity, plotted as the abscissa in terms of deposit height, was grouped in steps of 0.5 metres.

- Within the intensity class of 0.5 metres, the statistical spread of the vulnerability values is low (0.00-0.07), the mean vulnerability is 0.02 . 


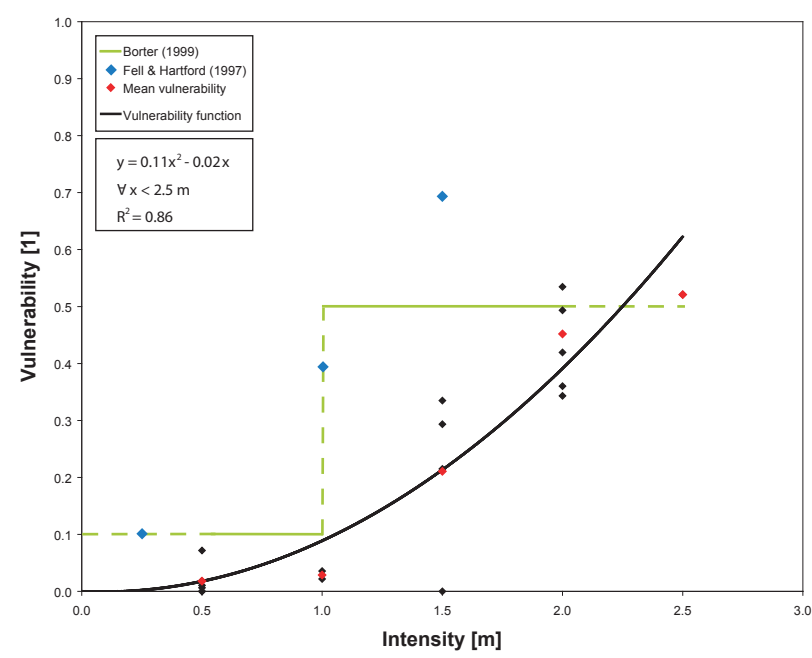

Fig. 3. Relationship between debris flow intensity $x$ and vulnerability $y$ expressed by a second order polynomial function for $x<2.5 \mathrm{~m}$. Results from the study site are indicated by black dots, the corresponding mean vulnerability is indicated by red dots. In addition, mean vulnerability values published by Borter (1999) are shown by green lines; values not explicitly specified are dashed. Mean vulnerability values by Fell and Hartford (1997) are represented by blue dots assuming low intensity to be $0.25 \mathrm{~m}$, medium intensity to be $1.0 \mathrm{~m}$, high intensity to be $1.5 \mathrm{~m}$.

- Within the intensity class of 1.0 metres, the statistical spread of the vulnerability values is low $(0.02-0.04)$, the mean vulnerability is 0.03 .

- Within the intensity class of 1.5 metres, the statistical spread of the vulnerability is remarkable $(0.00-0.33)$, the mean vulnerability is 0.21 .

- Within the intensity class of 2.0 metres, the statistical spread of the vulnerability is again remarkable $(0.34$ 0.53 ), the mean vulnerability is 0.45 .

- The intensity class of 2.5 metres is only applicable to one building, with a vulnerability of 0.52 . Even if due to limited data this value may presumably change in case more records are available, a considerable increase in vulnerability is detectable in comparison to lower process intensities.

In general, the results suggest a low vulnerability if the process intensity is low and an increased vulnerability if the process intensity is higher. In detail, the data do not suggest a linear increase in vulnerability, which is a result of the specific process characteristics. Low debris flow intensities cause noticeably less damage than medium and high intensities. Thus, the relationship between debris flow intensity $x$ and vulnerability $y$ was found to fit best to the data by a second order polynomial function for all intensities $x<2.5 \mathrm{~m}$, see Eq. (2).

$y=0.11 x^{2}-0.02 x$
The coefficient of determination $R^{2}$ is 0.86 , which seems to be comparatively sound with respect to the amount of data available. In addition, mean vulnerability values for debris flow risk published by Borter (1999) and Fell and Hartford (1997) are shown in Fig. 3 by a green line and by blue dots.

The vulnerability function developed in this study (values between 0.00 and 0.07 ) seems to be consistent with the suggestions of Borter (1999) for intensities $<1.0 \mathrm{~m}$, even if for relatively small intensities no sound statements are traceable. For intensities between $1.0 \mathrm{~m}$ and $1.5 \mathrm{~m}$, the values of Borter overestimate the function developed within this study. This might be a result of the stepped structure of Borter's values; a sudden increase in vulnerability of 0.4 related to the intensity of $1.0 \mathrm{~m}$ is not supported by the findings within the Wartschenbach catchment. However, since Borter's values origin from experts' assumptions and approximations, the considerable increase related to a process intensity of $1.0 \mathrm{~m}$ might be an artefact of the method.

Due to the study design representing an assumption for buildings in Australia, where timber constructions are common and thus higher susceptibility for destruction result, the suggestions made by Fell and Hartford (1997) overestimate vulnerability function presented in Fig. 3. Furthermore, the authors assumed more or less linearity in the vulnerability curve in dependence on debris flow intensities, which can neither be supported by the results presented above, nor by studies performed in the Swiss Alps (Romang et al., 2003).

In addition, the analysis of the data had shown that the vulnerability of buildings affected by medium debris flow intensities $(1.00-1.50 \mathrm{~m})$ is highly dependent on whether or not the entrained material harms the interior of the building (i.e., by an intrusion of material through openings such as doors, wells and windows). These findings support previous work carried out by Romang et al. (2003). Consequently, local protection measures such as deflection walls and specially designed closure structures for at-grade openings definitely play a major role in reducing buildings' vulnerability, particularly with respect to low and medium debris flow intensities.

Following the 1990s events, some of the homeowners constructed local protection for their individual buildings (Fig. 4). Though reinforced concrete walls may shield buildings from possible future torrent events, no integral protection concept had been implemented for the whole village; the community disregarded a planned overall protection concept developed by the Austrian Torrent and Avalanche Control Service in the aftermath of the 1990s events: Few buildings are protected by high concrete walls (Fig. 5), while others are surrounded by lower (garden) walls, earth-filled dams or even lattice fencing. As a result, in case of upcoming events, the material will be drained further downslope and cause damage at those buildings where the local protection is not sufficient. 


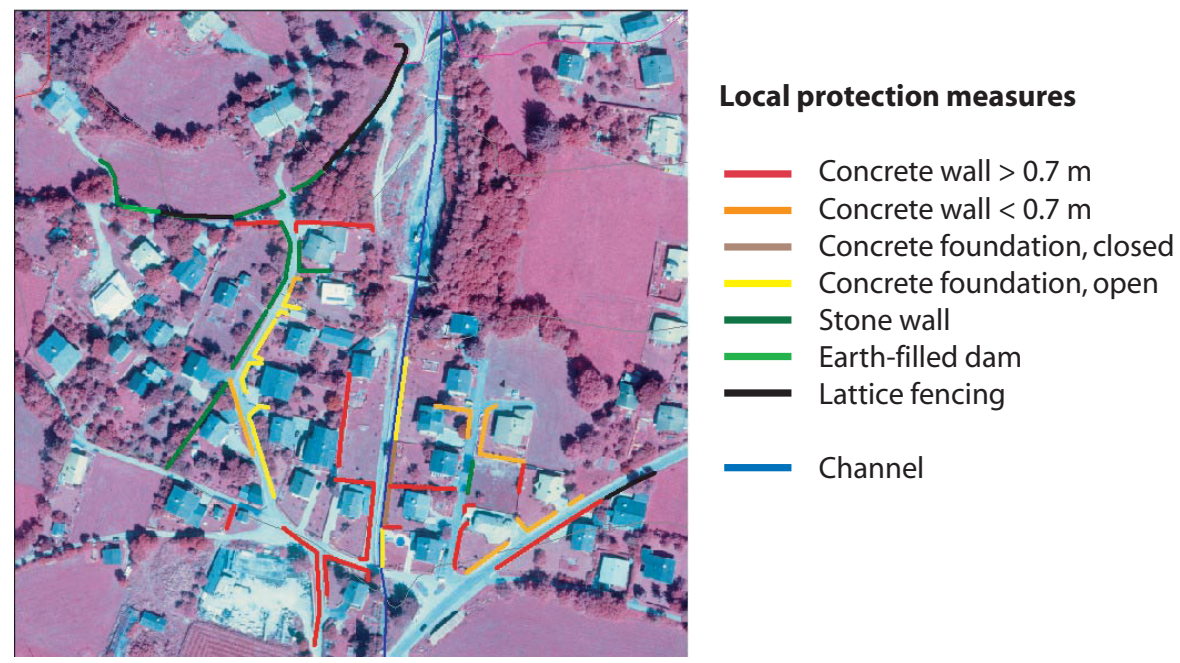

Fig. 4. Different types of local protection measures constructed by the homeowners in the Wartschensiedlung village.

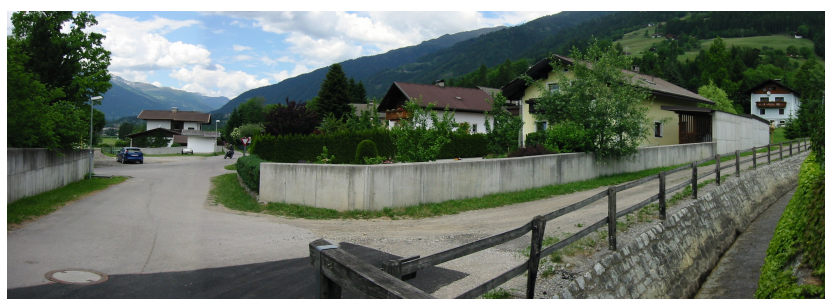

Fig. 5. Local protection measures in the Wartschensiedlung village.

\section{Conclusions}

If risk analyses are carried out with respect to the probable maximum loss, a vulnerability value of 1 will generally be assigned to exposed elements at risk (Glade, 2003). However, such solutions are not very valuable with respect to a better understanding of the vulnerability of elements at risk to torrent events. A general strategy in determining vulnerability of elements at risk to specific events is still missing. Until now, vulnerability models are mainly based on plausibility issues, expert knowledge, conceptual approaches, and assessments of historical data. Hence, they are for the most part based on qualitative statements on observed damage. Furthermore, this data is hardly transferable to future scenarios since the impact force of the process and thus the process intensity is not known. In the previous section, an empirical vulnerability function for debris flow intensities $<2.5 \mathrm{~m}$ was presented for an alpine test site. It had been shown that this function follows a polynomial distribution. However, by definition, vulnerability ranges from 0 and 1 . Consequently, for process intensities $\geq 2.5-3 \mathrm{~m}$, vulnerability cannot be satisfyingly mirrored by such a polynomial, because an overall vulnerability function has to fulfil the constraint shown in Eq. (3). On the other hand, such high process intensities generally result in a total loss of the building since the arising efforts to repair the damage will exceed the expenditures necessary for a completely new construction (Oberndorfer, 2007).

$$
\lim _{x \rightarrow \infty} f_{(x)}=1
$$

The presented method followed a spatial approach, and was based on process intensities, the volume of elements at risk and average reconstruction values in dependence of the surface area on an object basis. Nevertheless, since vulnerability was defined using an actuarial approach, the relation between reconstruction values and losses principally allows a wider application in regions with different economic background.

Vulnerability is highly dependent on the construction material used for exposed elements at risk. The buildings studied within the test site were constructed by using brick masonry and concrete, a typical construction design in post1950s building craft in alpine countries. Consequently, the presented intensity-vulnerability relationship is applicable to this mixed construction type within European mountains. However, a wider application of the presented method to additional test sites would allow for further improvement of the results and would support an enhanced standardisation of the vulnerability function.

\section{Appendix A}

In Austria, natural hazards are not subject to compulsory insurance. Apart from the inclusion of losses resulting from hail, pressure due to snow load, rock fall and sliding processes in an optional storm damage insurance, no standardised product is currently available on the national insurance market. Moreover, the terms of business of this storm damage insurance explicitly exclude coverage of damage due to 
avalanches, floods and inundation, debris flows, earthquakes and similar extraordinary natural events (Schieferer, 2006).

Furthermore, according to the constitution of the Republic of Austria, catastrophes resulting from natural hazards do not fall under the national jurisdiction. Thus, the responsibility for an aid to repair damage resulting from natural hazards generally rests with the federal states. As a consequence, any claim for damages is subject to a considerable insecurity, and any natural and artificial person has to take individual precautions. Thus, the society seems to be highly vulnerable to natural hazards in Austria.

However, the federal government enacted a law for financial support of the federal states in case of extraordinary losses due to natural hazards in the aftermath of the avalanche winter in 1951. The so-called "law related to the catastrophe fund" (Katastrophenfondsgesetz) is the legal basis for the provision of national resources for

- preventive actions to construct and maintain torrent and avalanche control measures, and

- financial aids for the federal states to enable them to compensate individuals and private enterprises for losses due to natural hazards

in Austria. The budget of the catastrophe fund originates from a defined percentage (since 1996: 1.1\%) of the federal share on the income taxes, capital gains taxes, and corporation taxes. The prescribed maximum reserves amount to EUR 29 million (Republik Österreich, 1996).

Acknowledgements. The underlying studies were funded by the European Commission (Contract 018412) within the IRASMOS project (Integral Risk Management of Extremely Rapid Mass Movements). The authors would like to express their sincere thanks to the IRAMSOS consortium for stimulating discussions of the presented results, above all M. Naaim and T. Faug. Furthermore, the authors wish to kindly acknowledge the valuable efforts by J. Douglas and another anonymous reviewer for an improvement of the manuscript.

Edited by: M. Keiler, S. Fuchs, and T. Glade

Reviewed by: J. Douglas and another anonymous referee

\section{References}

ALD: Australian Landslide Database, http://www.ga.gov.au/oracle/ landslid/landsl_online.jsp, 2007 (access May 30, 2007).

Alexander, D.: Natural disasters, Routledge, London, 1993.

Alexander, D.: Vulnerability to landslides, edited by: Glade, T., Anderson, M. and Crozier, M., Landslide hazard and risk, John Wiley \& Sons, Chichister, 175-198, 2005.

Amendola, A.: Approaches to risk analysis in the European Union, edited by: Kirchsteiger, C., Risk assessment and management in the context of the Seveso II Directive, Elsevier, Amsterdam, 3-18, 1998.
Barbolini, M., Cappabianca, F., and Sailer, R.: Empirical estimate of vulnerability relations for use in snow avalanche risk assessment, edited by: Brebbia, C., Risk Analysis IV, WIT Press, Southampton, 533-542, 2004.

Bell, R. and Glade, T.: Quantitative Risk Analysis for Landslides - Examples from Bíldudalur, NW Iceland, Nat. Hazards Earth Syst. Sci., 4, 117-131, 2004, http://www.nat-hazards-earth-syst-sci.net/4/117/2004/.

Bogard, W.: Bringing social theory to hazards research: conditions and consequences of the mitigation of environmental hazards, Sociological Perspectives, 31, 147-168, 1989.

Bohle, H.-G., Downing, T. and Watts, M.: Climate change and social vulnerability: the sociology and geography of food insecurity, Global Environmental Change, 4, 37-48, 1994.

Borter, P.: Risikoanalyse bei gravitativen Naturgefahren, Bundesamt für Umwelt, Wald und Landschaft, Bern, 1999.

Burton, I. and Kates, R.: The perception of natural hazards in resource management, Natural Resour. J., 4, 412-441, 1964.

Burton, I., Kates, R., and White, G.: The environment as hazard, Guilford Press, New York, 1993.

BUWAL, BWW and BRP: Berücksichtigung der Massenbewegungsgefahren bei raumwirksamen Tätigkeiten, Bundesamt für Umwelt, Wald und Landschaft, Bundesamt für Wasserwirtschaft, Bundesamt für Raumplanung, Bern und Biel, 1997.

BWW, BRP and BUWAL: Berücksichtigung der Hochwassergefahren bei raumwirksamen Tätigkeiten, Bundesamt für Wasserwirtschaft, Bundesamt für Raumplanung, Bundesamt für Umwelt, Wald und Landschaft, Biel und Bern, 1997.

Cannon, T.: A hazard need not a disaster make: vulnerability and the causes of "natural" disasters, edited by: Merriman, P. and Browitt, C., Natural disasters: Protecting vulnerable communities, Thomas Telford, London, 92-105, 1993.

Cardinali, M., Reichenbach, P., Guzzetti, F., Ardizzone, F., Antonini, G., Galli, M., Cacciano, M., Castellani, M. and Salvati, P.: A geomorphological approach to the estimation of landslide hazards and risk in Umbria, Central Italy, Nat. Hazards Earth Syst. Sci., 2, 57-72, 2002,

http://www.nat-hazards-earth-syst-sci.net/2/57/2002/.

Comfort, L., Wisner, B., Cutter, S., Pulwarty, R., Hewitt, K., OliverSmith, A., Wiener, J., Fordham, M., Peacock, W. and Krimgold, F.: Reframing disaster policy: the global evolution of vulnerable communities, Environmental Hazards, 1, 39-44, 1999.

Cutter, S.: Living with risk, Edward Arnold, London, 1993.

Cutter, S.: Vulnerability to environmental hazards, Progr. Human Geogr., 20, 529-539, 1996.

Douglas, J.: Physical vulnerability modelling in natural hazard risk assessment, Nat. Hazards Earth Syst. Sci., 7, 283-288, 2007, http://www.nat-hazards-earth-syst-sci.net/7/283/2007/.

Dow, K.: Exploring differences in our common future(s): the meaning of vulnerability to global environmental change, Geoforum, 23, 417-436, 1992.

Dow, K. and Downing, T.: Vulnerability research: where things stand. Human Dimensions Quarterly, 1, 3-5, 1995.

Downing, T.: Vulnerability to hunger and coping with climate change in Africa, Global Environmental Change, 1, 365-380, 1991.

Fell, R.: Landslide risk assessment and acceptable risk, Canadian Geotechnical Journal, 31, 261-272, 1994.

Fell, R. and Hartford, D.: Landslide risk management, edited by: 
Cruden, D. and Fell, R., Landslide risk assessment, Balkema, Rotterdam, 51-109, 1997.

Finlay, P.: The risk assessment of slopes, PhD Thesis, School of Civil Engineering, University of New South Wales, Sydney, Australia, 1996.

Fraefel, M., Schmid, F., Frick, E. and Hegg, C.: 31 Jahre Unwettererfassung in der Schweiz, Proc. Internationales Symposion Interpraevent - Riva del Garda, May 24-27, I/45-I/56, 2004.

Gabor, T. and Griffith, T.: The assessment of community vulnerability to acute hazardous materials incidents, Journal of Hazardous Materials, 8, 323-333, 1980.

German Advisory Council on Global Change (Ed.): World in transition: strategies for managing global environmental risks, Annual report, Springer, Berlin, 1998.

Gilard, O. and Givone, P.: Flood risk management: new concepts and methods for objective negotiations, edited by: Leavesley, G., Lins, H., Nobilis, F., Parker, R., Schneider, V. and van der Ven, F., Destructive water: water-caused natural disasters, their abatement and control, IAHS Press, Oxfordshire, 145-155, 1997.

Glade, T.: Vulnerability assessment in landslide risk analysis, Die Erde, 134, 123-146, 2003.

Green, C., van der Veen, A., Wierstra, E., and Penning-Rowsell, E.: Vulnerability refined: analysing full flood impacts, edited by: Penning-Rowsell, E. and Fordham, M., Floods across Europe: flood hazard assessment, modelling and management, Middlesex University Press, London, 32-68, 1994.

Hübl, J., Ganahl, E. and Schnetzer, I.: Dokumentation Wartschenbach, IAN Report, 52, Institut für Alpine Naturgefahren, Universität für Bodenkultur, Wien, 2002.

Jónasson, K., Sigurðsson, S., and Arnalds, P.: Estimation of avalanche risk. Icelandic Meteorological Office, Reykjavík, 1999.

Kates, R.: The interaction of climate and society, edited by: Kates, R., Ausubel, J. and Berberian, M., Climate impact assessment, Wiley, New York, 3-36, 1985.

Keiler, M., Zischg, A., Fuchs, S., Hama, M. and Stötter, J.: Avalanche related damage potential - changes of persons and mobile values since the mid-twentieth century, case study Galtür, Nat. Hazards Earth Syst. Sci., 5, 49-58, 2005, http://www.nat-hazards-earth-syst-sci.net/5/49/2005/.

Keiler, M., Zischg, A. and Fuchs, S.: Methoden zur GIS-basierten Erhebung des Schadenpotenzials für naturgefahreninduzierte Risiken, edited by: Strobl, J. and Roth, C., GIS und Sicherheitsmanagement, Wichmann, Heidelberg, 118-128, 2006.

Kranewitter, H.: Liegenschaftsbewertung, Gesco, Wien, 2002.

Kunreuther, H., Novemsky, N., and Kahneman, D.: Making low probabilities useful, J. Risk Uncertainty, 23, 103-120, 2001.

Leone, F., Asté, J.-P., and Velásquez, E.: Contribution des constats d'endommagement au développement d'une méthodologie d'évaluation de la vulnérabilité appliquée aux phénomènes de mouvements de terrain, Bulletin de l'Association de Géographes, 350-371, 1995.

Leone, F., Asté, J.-P., and Leroi, E.: L'évaluation de la vulnérabilité aux mouvements du terrain: Pour une meilleure quantification du risque, Revue de Géographie Alpine, 84, 35-46, 1996.

Liu, X. and Lei, J.: A method for assessing regional debris flow risk: an application in Zhaotong of Yunnan Province (SW China), Geomorphology, 52, 181-191, 2003.

Liverman, D.: Vulnerability to global environmental change, edited by: Kasperson, R., Dow, K., Golding, D. and Kasperson, J., Understanding global environmental change: the contributions of risk analysis and management, Clark University, Worcester, 2744, 1990.

Michael-Leiba, M., Baynes, F., Scott, G., and Granger, K.: Regional landslide risk to the Cairns community, Nat. Hazards, 30, 233-249, 2003.

Mileti, D.: Disasters by design, Joseph Henry Press, Washington, 1999.

Mitchell, J.: Hazards research, edited by: Gaile, G. and Willmott, C., Geography in America, Merill, Colombus, 410-424, 1989.

Oberndorfer, S., Fuchs, S., Rickenmann, D., and Andrecs, P.: Vulnerabilitätsanalyse und monetäre Schadensbewertung von Wildbachereignissen in Österreich, BFW-Bericht, 139, Bundesausbildungs- und Forschungszentrum für Wald, Naturgefahren und Landschaft, Wien, 2007.

O'Keefe, P., Westgate, K., and Wisner, B.: Taking the naturalness out of natural disasters, Nature, 260, 566-567, 1976.

Petak, W. and Atkisson, A.: Natural hazard risk assessment and public policy, Springer, New York, 1982.

Pijawka, K. and Radwan, A.: The transportation of hazardous materials: risk assessment and hazard management, Dangerous Properties of Industrial Materials Report, September/October, 2-11, 1985.

Rautela, P. and Lakhera, R.: Landslide risk analysis between Giri and Tons Rivers in Himachal Himalaya (India), International Journal of Applied Earth Observation and Geoinformation, 2, 153-160, 2000.

Republik Österreich: Katastrophenfondsgesetz 1996, BGB1 201/1996, 1996.

Romang, H.: Wirksamkeit und Kosten von WildbachSchutzmassnahmen, Verlag des Geographischen Instituts der Universität Bern, Bern, 2004.

Romang, H., Kienholz, H., Kimmerle, R., and Böll, A.: Control structures, vulnerability, cost-effectiveness - a contribution to the management of risks from debris torrents. edited by: Rickenmann, D. and Chen, C., Debris-flow hazards mitigation: mechanics, prediction, and assessment, Millpress, Rotterdam, 13031313, 2003.

Schieferer, W.: Abwicklungsfragen im versicherungsrechtlichen Umfeld von Naturgefahren - Zukunftsperspektive der privaten Naturkatastrophen-Vorsorge nach dem Hochwasserereignis vom 23. August 2005, edited by: Fuchs, S., Khakzadeh, L. and Weber, K., Recht im Naturgefahrenmanagement. StudienVerlag, Innsbruck, 115-122, 2006.

Schuster, R. and Fleming, R.: Economic losses and fatalities due to landslides, Bulletin of the Association of Engineering Geologists, 23, 11-28, 1986.

Smith, K.: Environmental hazards, Routledge, London, 2001.

Susman, O., O'Keefe, P., and Wisner, B.: Global disasters: a radical interpretation, edited by: Hewitt, K., Interpretations of calamity, Allen \& Unwin, Boston, 264-283, 1983.

Timmerman, P.: Vulnerability, resilience and the collapse of society, Environmental Monograph, 1, Institute of Environmental Studies, University of Toronto, 1981.

UNDRO: Natural disasters and vulnerability analysis, Office of the United Nations Disaster Relief Co-ordinator, Geneva, 1982.

UNDRO: Mitigation natural disasters: phenomena, effects, and options. A manual for policy makers and planners, Office of the 
United Nations Disaster Relief Co-ordinator, Geneva, 1991.

United Nations: Living with risk. United Nations, Geneva, 2004.

Varnes, D.: Landslide hazard zonation: a review of principles and practice, UNESCO, Paris, 1984.

Watts, M. and Bohle, H.-G.: The space of vulnerability: the causal structure of hunger and famine, Human Geogr., 17, 43-67, 1993.

Weichselgartner, J.: Disaster mitigation: the concept of vulnerability revisited, Disaster Prevention and Management, 10, 85-94, 2001.

Weichselgartner, J. and Bertens, J.: Natural disasters: acts of God, nature or society, edited by: Brebbia, C., Risk Analysis II, WIT Press, Southampton, 3-12, 2000.
White, G.: Natural hazards research, edited by: Chorley, R., Directions in Geography, Menthuen, London, 193-216, 1973.

Wilhelm, C.: Wirtschaftlichkeit im Lawinenschutz, Mitt. Eidgenössisches Institut für Schnee- und Lawinenforschung, 54, Davos, 1997.

Wisner, B.: Assessment of capability and vulnerability, edited by: Bankoff, G., Frerks, G. and Hilhorst, D., Mapping vulnerability, Earthscan, London, 183-193, 2004.

Wisner, B., Blaikie, P., Cannon, T., and Davis, I.: At risk, Routledge, London, 2004. 